\title{
Pain-Related Fear and Its Disabling Impact in Hypermobile Adolescents With Chronic Musculoskeletal Pain
}

Citation for published version (APA):

van Meulenbroek, T., Huijnen, I. P. J., Wiertz, C. M. H., \& Verbunt, J. A. (2017). Pain-Related Fear and Its Disabling Impact in Hypermobile Adolescents With Chronic Musculoskeletal Pain. Journal of Orthopaedic \& Sports Physical Therapy, 47(10), 775-781. https://doi.org/10.2519/jospt.2017.7282

Document status and date:

Published: 01/10/2017

DOI:

10.2519/jospt.2017.7282

Document Version:

Publisher's PDF, also known as Version of record

\section{Document license:}

Taverne

Please check the document version of this publication:

- A submitted manuscript is the version of the article upon submission and before peer-review. There can be important differences between the submitted version and the official published version of record.

People interested in the research are advised to contact the author for the final version of the publication, or visit the DOI to the publisher's website.

- The final author version and the galley proof are versions of the publication after peer review.

- The final published version features the final layout of the paper including the volume, issue and page numbers.

Link to publication

\footnotetext{
General rights rights.

- You may freely distribute the URL identifying the publication in the public portal. please follow below link for the End User Agreement:

www.umlib.nl/taverne-license

Take down policy

If you believe that this document breaches copyright please contact us at:

repository@maastrichtuniversity.nl

providing details and we will investigate your claim.
}

Copyright and moral rights for the publications made accessible in the public portal are retained by the authors and/or other copyright owners and it is a condition of accessing publications that users recognise and abide by the legal requirements associated with these

- Users may download and print one copy of any publication from the public portal for the purpose of private study or research.

- You may not further distribute the material or use it for any profit-making activity or commercial gain

If the publication is distributed under the terms of Article $25 \mathrm{fa}$ of the Dutch Copyright Act, indicated by the "Taverne" license above, 


\title{
RESEARCH REPORT
}

\author{
THIJS VAN MEULENBROEK, PT, MSc $c^{1,2}$ • IVAN P.J. HUIJNEN, PT, PhD ${ }^{1,2}$
}

CARLIJN M.H. WIERTZ, MD ${ }^{1}$ • JEANINE A. VERBUNT, MD, $\mathrm{PhD}^{1,2}$

\section{Pain-Related Fear and Its Disabling Impact in Hypermobile Adolescents With Chronic Musculoskeletal Pain}

C hronic pain is a common occurrence among adolescents. Up to $25 \%$ of all schoolchildren and adolescents report chronic pain. ${ }^{29,30}$ Along with abdominal pain and headache, chronic musculoskeletal pain (CMP) is one of the most frequently reported pain complaints in adolescents.9, ${ }^{9,29}$ In adolescents with CMP, pain complaints without a specific diagnosis often relate to muscular, ligamentous, bony, or joint structures and last for longer than 3 months. ${ }^{28}$ The incidence of CMP is reported to be higher among girl ${ }^{26,29}$ and increases with age during adolescence. ${ }^{29}$ In approximately $40 \%$ of adolescents

o STUDY DESIGN: Cross-sectional study.

O BACKGROUND: Chronic musculoskeletal pain (CMP) has a negative impact on physical functioning. During adolescence, joint hypermobility is a potential risk factor for developing CMP, and pain-related fear contributes to the persistence of CMP. Whether pain-related fear and hypermobility are related, and even reinforce each other, resulting in a stronger association with perceived level of disability, is still unknown.

OBJECTIVES: To evaluate whether pain-related fear has a stronger association with disability in hypermobile compared to nonhypermobile adolescents with CMP.

O METHODS: The study included 116 adolescents with CMP. The presence of hypermobility was assessed using the Beighton score. Measures of pain intensity, age, sex, and pain-related fear were collected and included in the multivariable model. Hierarchical regression analysis, with disability as with CMP, pain has a considerable disabling impact. ${ }^{16,21,25}$ Chronic musculoskeletal pain has a negative impact on physical functioning, mood, social functioning, and family, reducing the adolescent's quality of life. , $^{8,1720,21,28}$ In adolescents

the dependent variable, was used to examine the interaction between hypermobility and pain-related fear.

RESULTS: Hypermobile adolescents with CMP do not have more pain-related fear compared to nonhypermobile adolescents with CMP. There was no interaction effect between hypermobility and pain-related fear in explaining disability $(\beta=$ $.20, P=.42$ ). Similarly, perceived harmfulness of balance-related activities was not more strongly associated with disability in hypermobile adolescents with CMP.

- CONCLUSION: The association of pain-related fear with the perceived level of disability is not more pronounced in hypermobile compared to nonhypermobile adolescents with CMP. J Orthop Sports Phys Ther 2017;47(10):775-781. Epub 12 Sep 2017. doi:10.2519/jospt.2017.7282

KEY WORDS: Beighton, disability, joint hypermobility syndrome, perceived harmfulness with CMP, higher pain intensity has been shown to be associated with greater disability. ${ }^{13,41}$

Despite a broad array of medical diagnoses, only $10 \%$ to $30 \%$ of pain complaints can be explained based on a specific somatic disease. ${ }^{19,23}$ Because there is not always a somatic solution to explain CMP, a biopsychosocial approach to the management of CMP should be considered. ${ }^{28}$ In adults, the fear-avoidance model has been proposed and shown to explain the disabling role of pain-related fear. ${ }^{22,45,50}$ This model posits that catastrophizing thoughts may lead to the development of pain-related fear, thus leading to avoidance of feared activities. Over the long term, this avoidance behavior may result in disability, depression, and disuse, further fueling the vicious circle of disabling CMP. ${ }^{46-49}$ Recently, more evidence has become available to confirm that this model can be applied to explain pain-related disability in the pediatric and adolescent populations. ${ }^{2,34}$

Recent evidence has also shown that hypermobility is a risk factor for developing CMP. ${ }^{39,43}$ Generalized joint hypermobility $(\mathrm{GJH})$ is characterized by generalized joint laxity and increased joint mobility. In children with CMP, the prevalence of GJH is $40 \%$ to $48 \%{ }^{14,33,42}$ This number far exceeds the prevalence 
of GJH in the general child population $(19.2 \%) .{ }^{6}$ Generalized joint hypermobility associated with pain and symptoms such as arthralgia, soft tissue injury, and joint instability is referred to as joint hypermobility syndrome. Studies in children and adolescents showed that joint hypermobility syndrome is characterized by decreased muscle strength,$^{10}$ impaired proprioception, ${ }^{10}$ disabling fatigue,$^{52}$ reduced balance, ${ }^{32}$ and problems with gait, falls, and coordination. ${ }^{1}$ In adults, an increased incidence of psychiatric symptoms, including anxiety disorders, ${ }^{3,11}$ panic disorders, ${ }^{12,37}$ and depression,, 437 was also found to be associated with joint hypermobility syndrome.

A study by Scheper et $\mathrm{al}^{31}$ has shown that young healthy adults with GJH tend to avoid sports and outdoor activities and to prefer more stable activities like cycling. In view of their sense of impaired balance, this avoidance behavior is hypothesized to be a coping strategy to avoid joint luxation or injury and thus prevent the development of musculoskeletal complaints. Therefore, it could be assumed that pain-related fear and, more specifically, the perceived harmfulness of balance-related activities are more pronounced in hypermobile adolescents with CMP compared to adolescents with CMP who have no hypermobility, possibly resulting in avoidance behavior leading to impaired daily functioning. In the long term, impaired daily functioning may also result in a further decrease in muscle strength. For hypermobile adolescents with CMP, loss of muscle strength might act to further reduce joint stability, resulting in a higher risk of activities such as walking and problems such as falls and poor coordination causing the onset of pain. This might explain the higher prevalence of hypermobility in adolescents with $\mathrm{CMP}^{14,33,42}$ compared to the general adolescent population. ${ }^{6}$ Whether hypermobile adolescents with CMP have more pain-related fear compared to nonhypermobile adolescents with CMP and whether pain-related fear and being hypermobile reinforce each other, resulting in a stronger association with perceived disability, are still unknown.

Therefore, the aim of this study was to evaluate whether pain-related fear has a stronger association with disability in hypermobile compared to nonhypermobile adolescents with CMP. In addition, we explored whether the perceived harmfulness of balance-related activities had a stronger association with disability in hypermobile compared to nonhypermobile adolescents with CMP.

\section{METHODS}

\section{Participants}

DOLESCENTS (11 TO 21 YeARS OF $\triangle$ age) with CMP, who were referred to the university outpatient rehabilitation clinic specializing in pain rehabilitation (Adelante/Maastricht University Medical Center+, Maastricht, the Netherlands) between June 2012 and December 2015, were included in this cross-sectional study. Inclusion criteria were (1) nonspecific musculoskeletal pain for longer than 3 months, (2) not diagnosed with a specific somatic disorder that could explain the current pain problem (eg, neurological, orthopaedic, or rheumatoid disorders), and (3) sufficient proficiency in the Dutch language to complete the questionnaires.

The age range of 11 to 21 years was consistent with the definition of adolescents by the American Academy of Pediatrics, ${ }^{15}$ which defines adolescence as including 3 stages: early adolescence, 11 to 14 years of age; middle adolescence, 15 to 17 years of age; and late adolescence, 18 to 21 years of age.

\section{Procedure}

Adolescents were referred to the university outpatient rehabilitation clinic for a consultation with a physician in rehabilitation medicine. All patients were asked to complete web-based questionnaires. Questionnaires were part of the regular health care procedure. Patients were asked whether their data could be used anonymously for research purposes. If they agreed, the data were included in the research database. Ethical approval for this protocol was granted by the Medical Ethics Committee of the Academic Hospital Maastricht/Maastricht University, the Netherlands (NL41712.068.12/ METC 12-3-052). The set of questionnaires retrieved information on sociodemographic variables (age, sex, education level, and school absences), duration of pain, pain intensity, pain catastrophizing, functional disability, and fear of pain. A physician in rehabilitation medicine or a physical therapist assessed hypermobility using the Beighton score.

A subgroup of all participating adolescents received multidisciplinary rehabilitation treatment. In this group, the perceived harmfulness of activities was measured during the first session of the treatment program, at which time the patients had not yet received any educational instructions or multidisciplinary treatment.

\section{Measures}

Hypermobility The presence of hypermobility was assessed using the Beighton score, which consists of 5 functional tests, with a maximum score of 9 points (TABLE 1). The standardized Beighton

\begin{tabular}{|l|lll|}
\hline \multicolumn{1}{|c|}{ TABLE 1} & Beighton CRITERIA & & \\
& & & \\
\hline Joint Examination & Points & Criteria for Positive Sign \\
\hline Passive hyperextension of the little finger (measured bilaterally) & 2 & $>90^{\circ}$ \\
Passive thumb apposition to the forearm (measured bilaterally) & 2 & Thumb touches forearm \\
Elbow hyperextension (each elbow) & 2 & $>10^{\circ}$ \\
Knee hyperextension (each knee) & 2 & $>10^{\circ}$ \\
Standing trunk flexion with knees fully extended & 1 & Both palms flat on the floor \\
\hline
\end{tabular}


protocol is a valid instrument for the evaluation of generalized joint mobility in elementary school children. ${ }^{38}$ The full protocol for testing hypermobility is described by Smits-Engelsman et al. ${ }^{38}$ In the current study, this assessment was performed by a clinician. Based on the result of this assessment, the patients were assigned to 1 of 2 groups: patients who had a Beighton score of 5 or greater were assigned to the group with CMP and hypermobility, and patients who had a Beighton score of less than 5 were assigned to the group with CMP with no hypermobility. ${ }^{18}$

Sociodemographic Variables The following sociodemographic data were collected: age, sex, education level, duration of pain, school absences during the last year, and pain intensity. Pain intensity was measured using a $100-\mathrm{mm}$ visual analog scale (VAS), ranging from o (no pain) to 100 (worst pain imaginable). The participants rated their pain intensity (1) at the moment the questionnaire was completed, (2) for the worst/most severe pain experienced in the last week, and (3) for the least pain experienced in the last week. The mean of these 3 VAS scores was used in the analyses. The VAS seems to be reliable and valid in children older than 8 years. ${ }^{24,40}$

Functional Disability Functional disability was measured using the Functional Disability Inventory (FDI). The FDI is a questionnaire for children and adolescents that measures the perceived difficulty of performing activities at home, at school, and in recreational and social domains. It contains 15 items rated on a 5 -point scale ranging from $\mathrm{O}$ (no trouble) to 4 (impossible). The total score on the FDI ranges from 0 to 60 , with a higher score indicating greater pain-related disability. The reliability and validity of the FDI appear to be sufficient for assessing pain-related disabilities in children and adolescents. ${ }^{5,51}$

Fear of Pain The Fear of Pain Questionnaire-child report (FOPQ-C) was used to measure pain-related fear in children and adolescents with chronic pain. It con- tains 24 items and 2 scales, fear of pain and avoidance of activities. Each item is scored on a 5-point scale, ranging from 0 (strongly disagree) to 4 (strongly agree), and the total score ranges from 0 to 96 , with higher scores indicating higher levels of pain-related fear and avoidance. The FOPQ-C has been shown to be valid and reliable. ${ }^{36}$

Perceived Harmfulness The Photograph Series of Daily Activities for youth (PHODA-youth) was used to measure perceived harmfulness, or the indication to what extent the patient perceives the activity to be harmful for the painful body part. The PHODA-youth contains photographs of 51 age-specific daily life activities and social situations that are scored on the level of perceived harmfulness of performing these activities. The PHODA-youth consists of 3 categories: daily life and household activities, intensive physical activities, and social activities. Adolescents rate the photographs from o (completely harmless) to 10 (extremely harmful). Subscale scores for the 3 categories were obtained by summing the scores for all items in that subscale. To obtain a total score, all items were summed. The electronic version of the PHODA-youth has been found to be valid and reliable. ${ }^{44}$

For the current study, a subscale of the perceived harmfulness of balancerelated activities (PHODA-balance) was developed. Two authors, a physical therapist (T.M.) and a physiatrist (J.V.), independently scored all 51 age-specific daily life activities and social situations as yes or no, depending on their relation to balance. If both authors marked an activity as yes, then the activity was added to the PHODA-balance. In instances of disagreement, a third author (I.H.), a physical therapist, made the final decision whether to include the activity in the PHODA-balance. Seven activities were selected as activities related to balance, 6 from the PHODA physical activities subscale and 1 from the PHODA daily life and household activities subscale. To obtain a subscale score on the PHODA-balance, scores on the 7 items were summed, as are scores on the traditional subscales. The selected activities were (item 5) putting pants on, (item 20) participating in physical exercise/gym, (item 28) dancing/ sports, (item 30) running, (item 32) kicking a ball, (item 35) jumping over something, and (item 36) balancing on 1 leg.

Pain Catastrophizing The Pain Catastrophizing Scale for Children (PCS-C) measures catastrophizing thoughts about pain. It contains 13 items describing different thoughts and feelings that children and adolescents may experience when they are in pain, each rated on a 5 -point scale ranging from 0 (not at all) to 4 (extremely). The total score on the PCS-C can range from 0 to 52, with higher scores indicating more catastrophizing thoughts about pain. The PCS-C has been reported to be reliable and valid for children and adolescents. ${ }^{7}$

\section{Statistical Analysis}

The results were tested for normality using histograms and the KolmogorovSmirnov goodness-of-fit test. Descriptive data for the hypermobility and no-hypermobility groups were calculated. Where distribution of the data was normal, continuous data were shown as mean $\pm \mathrm{SD}$; where the distribution was nonnormal, the data were shown as median (interquartile range); and categorical data were presented as absolute frequencies or percentages. Differences between the hypermobility and no-hypermobility groups were analyzed using independentsamples $t$ tests, the Mann-Whitney $U$ test, the Kruskal-Wallis test, and the chisquare test.

To test the hypothesis that pain-related fear would have a stronger association with disability in adolescents in the hypermobility group compared to those in the no-hypermobility group, a hierarchical (blockwise entry) regression analysis was performed. Variables were entered in the regression model in 3 blocks. With the FDI as the dependent variable in the model, VAS, age, and sex (female, 0 ; male, 1) were introduced as independent variables in the first step to control 
for demographic variables and pain intensity. In the second step, pain-related fear (FOPQ-C) and the group variable of hypermobility (hypermobility/no hypermobility; dichotomous variable) were entered simultaneously. Finally, the interaction term $(\mathrm{FOPQ}-\mathrm{C} \times$ hypermobility/no hypermobility) was introduced in the third step. In case of a significant interaction, additional regression analyses were performed for hypermobility and no-hypermobility groups separately to identify influencing factors for disability.

First, the Pearson correlation between the FOPQ-C and PHODA-balance was calculated. The regression analysis was then repeated with the PHODA-balance instead of the FOPQ-C in the model, to explore whether the perceived harmfulness of balance-related activities had a stronger association with disability in hypermobile compared to nonhypermobile adolescents with CMP. For all regression analyses, a collinearity check was performed. Collinearity was considered a problem if the variance inflation factor was above $10 .^{27}$ The alpha level was set at .05. All statistical analyses were performed in IBM SPSS Statistics for Windows Version 23.0 (IBM Corporation, Armonk, NY).

\section{RESULTS}

\section{Descriptive Analyses}

A TOTAL OF 183 ADOLESCENTS (162 FEmale, 21 male) were asked if their data could be used anonymously for research purposes, and data from 116 adolescents were included in the current study. Sixty-seven adolescents were excluded from the analyses for the following reasons: 8 ultimately proved to have a specific somatic disorder explaining the current pain problem, 38 did not complete the questionnaires, and the Beighton scores of 21 potential participants were unknown. Of the 116 adolescents, only 45 received multidisciplinary treatment, and, for this reason, the PHODA-youth was only measured in this subgroup (FIGURE).

The characteristics of each group are presented in TABLE 2. No significant dif-

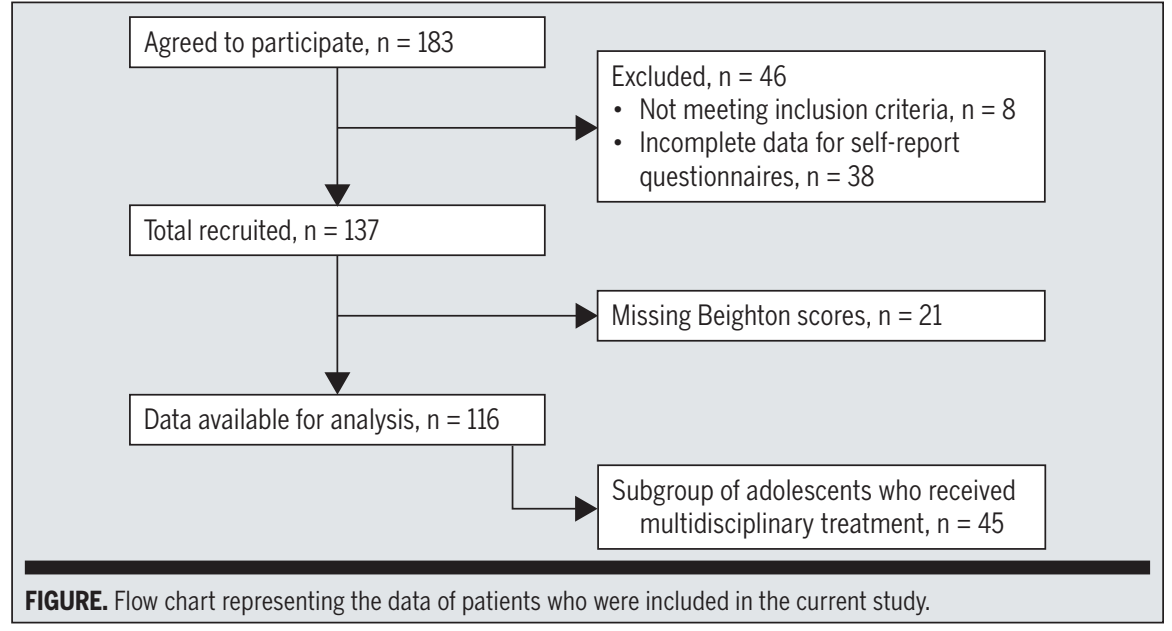

ferences were found between the hypermobility group and the no-hypermobility group with respect to sociodemographic variables such as age, sex, education level, and school absences. The duration of pain, VAS, PCS-C, FDI, FOPQ-C, and all PHODA outcomes also did not significantly differ between groups.

\section{The Association Between Pain-Related Fear, Hypermobility, and Disability}

TABLE 3 presents the outcome of the regression analysis with disability as the dependent variable. The inclusion of VAS, age, and sex as independent variables in the first step showed that no significant association with disability was found. In the second step, the FOPQ-C and the group variable of hypermobility/no hypermobility were added to the model, resulting in a significant model $\left(R^{2}=0.32\right.$, adjusted $\left.R^{2}=0.29, P<.001\right)$. Only the FOPQ-C was associated with disability $(\beta=.56, P<.001)$, indicating that a higher level of pain-related fear was associated with more disabilities. In the third step, the interaction term (FOPQ-C $\times$ hypermobility/no hypermobility) was added in the model, but it did not appear to be significantly associated with disability.

Before analyzing the association between PHODA-balance and disability, the Pearson correlation between the FOPQ-C and PHODA-balance was calculated $(r=$ $0.36, P=.01)$. Then, an identical proce- dure was performed using the PHODAbalance in a subgroup of adolescents who received multidisciplinary treatment instead of the FOPQ-C as the fear-related variable in the model. In the first step of the regression model, the VAS, age, and sex were introduced, but no significant association with disability was found. The PHODA-balance and the group variable of hypermobility/no hypermobility were added in the second step $\left(R^{2}=0.44\right.$, adjusted $\left.R^{2}=0.36, P<.001\right)$. Results showed that only the PHODA-balance was found to be associated with disability $(\beta=.64$, $P<.001$ ), indicating that higher perceived harmfulness of balance-related activities was associated with more disabilities. In the third step, the interaction term (PHODA-balance $\times$ hypermobility/no hypermobility) was added to the model, but no significant association with disability was found.

\section{DISCUSSION}

$\mathbf{T}$ HE RESULTS INDICATE THAT HYPERmobile adolescents with CMP do not have more pain-related fear compared to nonhypermobile adolescents with CMP, and that pain-related fear and being hypermobile do not reinforce each other in explaining the perceived level of disability. Further, the perceived harmfulness of balance-related activities was not more strongly associated with disability in hypermobile adolescents with CMP. 


\begin{tabular}{|c|c|c|c|}
\hline \multirow[t]{2}{*}{ TABLE 2} & \multicolumn{3}{|c|}{$\begin{array}{c}\text { Characteristics of the Study Sample } \\
\text { of Adolescents With Chronic } \\
\text { Musculoskeletal Pain* }\end{array}$} \\
\hline & HM Group $(n=40)$ & NHM Group $(n=76)$ & Test Statistics \\
\hline Sex (female/male), $\mathrm{n}$ & $36 / 4$ & $67 / 9$ & $X_{1}^{2}=0.09, P=.52$ \\
\hline Age, $y^{\dagger}$ & $16.0 \pm 2.4$ & $16.1 \pm 2.4$ & $t_{114}=0.23(-0.82,1.04)$ \\
\hline Education level, $n(\%)$ & & & $\mathrm{H}_{1}=0.01, P=.93$ \\
\hline Primary school & $2(5)$ & $5(6.6)$ & \\
\hline LGSE & $10(25)$ & $22(28.9)$ & \\
\hline HGSE & $11(27.5)$ & $17(22.4)$ & \\
\hline Preuniversity education & $7(17.5)$ & $10(13.2)$ & \\
\hline Vocational education & $9(22.5)$ & $17(22.4)$ & \\
\hline University of applied sciences & $1(2.5)$ & $4(5.3)$ & \\
\hline University & $0(0)$ & $1(1.3)$ & \\
\hline Duration of pain, $\mathrm{n}(\%)$ & & & $H_{1}=0.59, P=.44$ \\
\hline $3-6 \mathrm{mo}$ & $3(7.9)$ & $7(10.0)$ & \\
\hline $6-12 \mathrm{mo}$ & $10(26.3)$ & $20(28.6)$ & \\
\hline $1-5 y$ & $20(52.6)$ & $38(54.3)$ & \\
\hline$>5 y$ & $5(13.2)$ & $5(7.1)$ & \\
\hline School absences, $n(\%)$ & & & $\mathrm{H}_{1}=0.15, P=.70$ \\
\hline $0-14 d$ & $20(51.3)$ & $39(52.7)$ & \\
\hline $15-30 d$ & $8(20.5)$ & $9(12.2)$ & \\
\hline $1-3 \mathrm{mo}$ & $6(15.4)$ & $11(14.9)$ & \\
\hline $4-6 \mathrm{mo}$ & $3(7.7)$ & $6(8.1)$ & \\
\hline $7-12 \mathrm{mo}$ & $2(5.1)$ & $9(12.2)$ & \\
\hline VAS $^{\dagger}$ & $59.0 \pm 17.1$ & $56.8 \pm 18.3$ & $t_{99}=-0.58(-9.60,5.30)$ \\
\hline $\mathrm{FDI}^{+}$ & $22.4 \pm 10.2$ & $23.7 \pm 9.7$ & $t_{114}=0.69(-2.51,5.15)$ \\
\hline FOPQ-C ${ }^{\dagger}$ & $39.4 \pm 17.1$ & $39.1 \pm 14.1$ & $t_{114}=-0.09(-6.14,5.61)$ \\
\hline PCS-C $C^{\ddagger}$ & $22.8(12.0-31.8)$ & $20.5(12.3-28.3)$ & $U=1336, z=-1.07, P=.29$ \\
\hline PHODA-youth total\$s & $190.6 \pm 83.2$ & $154.1 \pm 97.1$ & $t_{43}=-1.22(-96.80,24.10)$ \\
\hline PHODA ADL subscale $e^{\ddagger}$ & $26.3(9.0-49.6)$ & $11.5(1.5-31.0)$ & $U=143, z=-1.82, P=.07$ \\
\hline PHODA PA subscale ${ }^{\dagger \S}$ & $126.8 \pm 47.3$ & $113.6 \pm 60.2$ & $t_{43}=-0.72(-50.00,23.60)$ \\
\hline PHODA SA subscale ${ }^{\dagger \S}$ & $30.3 \pm 22.0$ & $22.2 \pm 21.6$ & $t_{43}=-1.16(-22.20,6.00)$ \\
\hline PHODA-balance ${ }^{\dagger \S}$ & $33.0 \pm 12.9$ & $28.6 \pm 16.3$ & $t_{43}=-0.90(-14.40,5.50)$ \\
\hline \multicolumn{4}{|c|}{$\begin{array}{l}\text { Abbreviations: ADL, activities of daily living; FDI, Functional Disability Inventory; FOPQ-C, Fear } \\
\text { of Pain Questionnaire-child report; HGSE, higher general secondary education; HM, hypermobility } \\
\text { LGSE, lower general secondary education; NHM, no hypermobility; PA, physical activity; PCS-C, } \\
\text { Pain Catastrophizing Scale for Children; PHODA, Photograph Series of Daily Activities; SA, social } \\
\text { activities; VAS, visual analog scale. } \\
{ }^{*} \text { Values are mean } \pm \text { SD unless otherwise indicated. } \\
{ }^{+} \text {Normally distributed data. Values in parentheses in the test statistics column are 95\% confidence } \\
\text { interval. } \\
{ }^{*} \text { Nonnormally distributed data. Values are median (interquartile range). } \\
{ }^{\$} \text { Only measured in the subgroup that received treatment }(H M, n=14 ; N H M, n=31) .\end{array}$} \\
\hline
\end{tabular}

It was hypothesized that pain-related fear would be more prominent in hypermobile adolescents with CMP, possibly resulting in avoidance behavior leading to impaired daily functioning. This was hypothesized to result in a stronger association between pain-related fear and tion of the daily functioning of not only the hypermobile but also the nonhypermobile adolescents with CMP. Being hypermobile probably makes you more vulnerable to developing chronic pain, but once you have chronic pain, the level of fear, as reported in the current study, is associated with disability.

The current study also explored whether the perceived harmfulness of balance-related activities had a stronger association with disability in hypermobile compared to nonhypermobile adolescents with CMP. The results did not confirm this supposition. Earlier studies reported a positive association between perceived harmfulness and the level of disability. ${ }^{35,44}$ This association was also found between perceived harmfulness of balance-related activities and disability in the current study, but this association was not stronger in hypermobile compared to nonhypermobile adolescents with CMP. However, the current findings are based on a limited sample of 45 adolescents (14 hypermobile and 31 nonhypermobile), so the results should be considered with caution. Nevertheless, earlier studies reported decreased muscle strength, ${ }^{9}$ impaired proprioception, ${ }^{10}$ and reduced balance ${ }^{32}$ in hypermobile compared to nonhypermobile children and adolescents with CMP. Furthermore, adolescents with GJH prefer more stable activities (eg, walking and cycling) and tend to avoid dynamic activities. ${ }^{31}$ Therefore, it might be of interest to evaluate the perceived harmfulness of balance-related activities in adolescents with hypermobility in future studies.

As mentioned earlier, one limitation of the current study is the small number of adolescents who completed the PHODA-youth, resulting in insufficient power of the analysis that included the PHODAbalance. Furthermore, the selection of balance-related items (PHODA-balance) used in the current study, though made by experts, has not been validated. However, use of this subscale was necessary in this study to analyze the specific perceived harmfulness of balance-related 


\begin{tabular}{|c|c|c|c|c|c|}
\hline TABLE 3 & \multicolumn{5}{|c|}{$\begin{array}{l}\text { Regression ANALYsis With Disability } \\
\text { as THE DePENDENT VARIABLE* }\end{array}$} \\
\hline Independent Variable & B & $\beta^{\dagger}$ & $R^{2}$ & Adjusted $R^{2}$ & F Change \\
\hline Block 1 & & & 0.02 & -0.01 & 0.64 \\
\hline Sex & 0.05 & $0.00(-6.27,6.36)$ & & & \\
\hline Age & 0.20 & $0.05(-0.62,1.01)$ & & & \\
\hline VAS & 0.07 & $0.13(-0.04,0.18)$ & & & \\
\hline Block 2 & & & 0.32 & 0.29 & $21.39 \ddagger$ \\
\hline FOPQ-C & 0.37 & $0.56(0.26,0.48)^{\ddagger}$ & & & \\
\hline Group (HM/NHM) & -1.21 & $-0.06(-4.67,2.26)$ & & & \\
\hline Block 3 & & & 0.33 & 0.29 & 0.64 \\
\hline FOPQ $-\mathrm{C} \times \mathrm{HM} / \mathrm{NHM}$ & 0.09 & $0.20(-0.13,0.32)$ & & & \\
\hline \multicolumn{6}{|c|}{$\begin{array}{l}\text { Abbreviations: FOPQ-C, Fear of Pain Questionnaire-child report; HM, hypermobility; NHM, no } \\
\text { hypermobility; } V A S \text {, visual analog scale. } \\
{ }^{*} \text { Represented by the Functional Disability Inventory. } \\
{ }^{+} \text {Values in parentheses are } 95 \% \text { confidence interval. } \\
{ }^{*} P<.05 .\end{array}$} \\
\hline
\end{tabular}

activities. Further research is needed to confirm whether this selection of PHODA items offers a valid representation of balance-related activities. Another limitation is the cross-sectional design of the study, which meant that no causal relationships could be confirmed. However, if significant associations were not present in cross-sectional data, then it is unlikely that they would be present in a longitudinal cohort.

This study confirms earlier findings that pain-related fear is related to disability. ${ }^{2,34}$ It is therefore important that, in clinical practice, treatment of adolescents with CMP focus on a biopsychosocial approach. ${ }^{28}$ This has also been confirmed in the last few decades by several biopsychosocial rehabilitation programs for adults that focused on psychosocial influencing factors, and especially the influence of pain-related fear. ${ }^{22,50}$

\section{CONCLUSION}

$\mathbf{T}$ HE ASSOCIATION OF PAIN-RELATED fear with the perceived level of disability is not more pronounced in hypermobile compared to nonhypermobile adolescents with CMP. Perceived harmfulness of balance-related activities was not more strongly associated with disability in hypermobile adolescents with CMP. 0

\section{KEY POINTS}

FINDINGS: This study evaluated whether pain-related fear has a stronger association with disability in hypermobile compared to nonhypermobile adolescents with chronic musculoskeletal pain. IMPLICATIONS: The association between pain-related fear and the perceived level of disability is not more pronounced in hypermobile compared to nonhypermobile adolescents with chronic musculoskeletal pain.

CAUTION: In this study, a cross-sectional design was used and no causal relationships could be tested.

\section{REFERENCES}

1. Adib N, Davies K, Grahame R, Woo P, Murray KJ. Joint hypermobility syndrome in childhood. A not so benign multisystem disorder? Rheumatology (Oxford). 2005;44:744-750. https://doi. org/10.1093/rheumatology/keh557

2. Asmundson GJ, Noel M, Petter M, Parkerson HA. Pediatric fear-avoidance model of chronic pain: foundation, application and future directions. Pain Res Manag. 2012;17:397-405. https://doi. org/10.1155/2012/908061

3. Bulbena A, Gago J, Pailhez G, Sperry L, Fullana $M A$, Vilarroya 0 . Joint hypermobility syndrome is follow-up cohort study. Gen Hosp Psychiatry. 2011;33:363-370. https://doi.org/10.1016/j. genhosppsych.2011.03.004

4. Cederlöf $\mathrm{M}$, Larsson $\mathrm{H}$, Lichtenstein $\mathrm{P}$, Almqvist a risk factor trait for anxiety disorders: a 15-year
C, Serlachius E, Ludvigsson JF. Nationwide population-based cohort study of psychiatric disorders in individuals with Ehlers-Danlos syndrome or hypermobility syndrome and their siblings. BMC Psychiatry. 2016;16:207. https:// doi.org/10.1186/s12888-016-0922-6

5. Claar RL, Walker LS. Functional assessment of pediatric pain patients: psychometric properties of the Functional Disability Inventory. Pain. 2006;121:77-84. https://doi.org/10.1016/j. pain.2005.12.002

6. Clinch J, Deere K, Sayers A, et al. Epidemiology of generalized joint laxity (hypermobility) in fourteenyear-old children from the UK: a population-based evaluation. Arthritis Rheum. 2011;63:2819-2827. https://doi.org/10.1002/art.30435

7. Crombez G, Bijttebier P, Eccleston C, et al. The child version of the Pain Catastrophizing Scale (PCS-C): a preliminary validation. Pain. 2003;104:639-646. https://doi.org/10.1016/S0304-3959(03)00121-0

8. Eccleston C, Crombez G, Scotford A, Clinch J, Connell H. Adolescent chronic pain: patterns and predictors of emotional distress in adolescents with chronic pain and their parents. Pain. 2004;108:221-229. https://doi.org/10.1016/j. pain.2003.11.008

9. El-Metwally A, Salminen JJ, Auvinen A, Kautiainen H, Mikkelsson M. Prognosis of nonspecific musculoskeletal pain in preadolescents: a prospective 4-year follow-up study till adolescence. Pain. 2004;110:550-559. https:// doi.org/10.1016/j.pain.2004.03.021

10. Fatoye F, Palmer S, Macmillan F, Rowe P, van der Linden M. Proprioception and muscle torque deficits in children with hypermobility syndrome. Rheumatology (Oxford). 2009;48:152-157. https://doi.org/10.1093/rheumatology/ken435

11. Garcia-Campayo J, Asso E, Alda M. Joint hypermobility and anxiety: the state of the art. Curr Psychiatry Rep. 2011;13:18-25. https://doi. org/10.1007/s11920-010-0164-0

12. García Campayo J, Asso E, Alda M, Andres EM, Sobradiel N. Association between joint hypermobility syndrome and panic disorder: a case-control study. Psychosomatics. 2010;51:55-61. https://doi.org/10.1016/ S0033-3182(10)70659-9

13. Gauntlett-Gilbert J, Eccleston C. Disability in adolescents with chronic pain: patterns and predictors across different domains of functioning. Pain. 2007;131:132-141. https://doi. org/10.1016/j.pain.2006.12.021

14. Gedalia A, Press J, Klein M, Buskila D. Joint hypermobility and fibromyalgia in schoolchildren. Ann Rheum Dis. 1993;52:494-496. https://doi. org/10.1136/ard.52.7.494

15. Greydanus DE, Bashe P, American Academy of Pediatrics. Caring for Your Teenager: The Complete and Authoritative Guide. New York, NY: Bantam Books; 2003.

16. Huguet A, Miró J. The severity of chronic pediatric pain: an epidemiological study. J Pain. 2008;9:226-236. https://doi.org/10.1016/j. jpain.2007.10.015 
17. Hunfeld JA, Perquin CW, Duivenvoorden $\mathrm{HJ}$, et al. Chronic pain and its impact on quality of life in adolescents and their families. J Pediatr Psychol. 2001;26:145-153.

18. Juul-Kristensen B, Kristensen JH, Frausing $B$, Jensen DV, Røgind H, Remvig L. Motor competence and physical activity in 8-yearold school children with generalized joint hypermobility. Pediatrics. 2009;124:1380-1387. https://doi.org/10.1542/peds.2009-0294

19. Kashikar-Zuck $S$. Treatment of children with unexplained chronic pain. Lancet. 2006;367:380-382. https://doi.org/10.1016/ S0140-6736(06)68118-X

20. Kashikar-Zuck S, Goldschneider KR, Powers SW, Vaught MH, Hershey AD. Depression and functional disability in chronic pediatric pain. Clin J Pain. 2001;17:341-349.

21. Konijnenberg AY, Uiterwaal CS, Kimpen JL, van der Hoeven J, Buitelaar JK, de Graeff-Meeder ER. Children with unexplained chronic pain: substantial impairment in everyday life. Arch Dis Child. 2005;90:680-686. https://doi.org/10.1136/ adc. 2004.056820

22. Leeuw M, Goossens ME, Linton SJ, Crombez G, Boersma K, Vlaeyen JW. The fear-avoidance model of musculoskeletal pain: current state of scientific evidence. J Behav Med. 2007;30:77-94. https://doi.org/10.1007/s10865-006-9085-0

23. McGhee JL, Burks FN, Sheckels JL, Jarvis JN. Identifying children with chronic arthritis based on chief complaints: absence of predictive value for musculoskeletal pain as an indicator of rheumatic disease in children. Pediatrics. 2002;110:354-359. https://doi.org/10.1542/peds.110.2.354

24. McGrath PJ, Walco GA, Turk DC, et al. Core outcome domains and measures for pediatric acute and chronic/recurrent pain clinical trials: PedIMMPACT recommendations. J Pain. 2008;9:771-783. https://doi.org/10.1016/j. ppain.2008.04.007

25. Merlijn VP, Hunfeld JA, van der Wouden JC, Hazebroek-Kampschreur AA, Passchier J, Koes $B W$. Factors related to the quality of life in adolescents with chronic pain. Clin J Pain. 2006;22:306-315. https://doi.org/10.1097/01. ajp.0000177509.93523.68

26. Mikkelsson M, El-Metwally $A$, Kautiainen $H$, Auvinen A, Macfarlane GJ, Salminen JJ. Onset, prognosis and risk factors for widespread pain in schoolchildren: a prospective 4-year followup study. Pain. 2008;138:681-687. https://doi. org/10.1016/.pain.2008.06.005

27. Myers RH. Classical and Modern Regression With Applications. Pacific Grove, CA: Duxbury/ Thompson Learning; 1990.

28. O'Sullivan P, Beales D, Jensen L, Murray K, Myers T. Characteristics of chronic non-specific musculoskeletal pain in children and adolescents attending a rheumatology outpatients clinic: a cross-sectional study. Pediatr Rheumatol Online J. 2011;9:3. https://doi.org/10.1186/1546-0096-9-3

29. Perquin CW, Hazebroek-Kampschreur AA, Hunfeld $J A$, et al. Pain in children and adolescents: a common experience. Pain. 2000;87:51-58. https://doi.org/10.1016/S0304-3959(00)00269-4

30. Perquin CW, Hazebroek-Kampschreur AA, Hunfeld JA, van Suijlekom-Smit LW, Passchier J, van der Wouden JC. Chronic pain among children and adolescents: physician consultation and medication use. Clin J Pain. 2000;16:229-235.

31. Scheper M, de Vries J, Beelen A, de Vos R, Nollet F, Engelbert R. Generalized joint hypermobility, muscle strength and physical function in healthy adolescents and young adults. Curr Rheumatol Rev. 2014;10:117-125. https://doi.org/10.2174/157 3397111666150120112925

32. Schubert-Hjalmarsson E, Öhman A, Kyllerman M, Beckung E. Pain, balance, activity, and participation in children with hypermobility syndrome. Pediatr Phys Ther. 2012;24:339-344. https://doi.org/10.1097/PEP.0b013e318268e0ef

33. Siegel DM, Janeway D, Baum J. Fibromyalgia syndrome in children and adolescents: clinical features at presentation and status at follow-up. Pediatrics. 1998;101:377-382.

34. Simons LE, Kaczynski KJ. The Fear Avoidance model of chronic pain: examination for pediatric application. J Pain. 2012;13:827-835. https://doi. org/10.1016/j.jpain.2012.05.002

35. Simons LE, Pielech M, McAvoy S, et al. Photographs of Daily Activities-Youth English: validating a targeted assessment of worry and anticipated pain. Pain. 2017;158:912-921. https:// doi.org/10.1097/j.pain.0000000000000855

36. Simons LE, Sieberg CB, Carpino E, Logan D, Berde C. The Fear of Pain Questionnaire (FOPQ): assessment of pain-related fear among children and adolescents with chronic pain. J Pain. 2011;12:677-686. https://doi.org/10.1016/j. jpain.2010.12.008

37. Smith TO, Easton V, Bacon $\mathrm{H}$, et al. The relationship between benign joint hypermobility syndrome and psychological distress: a systematic review and meta-analysis. Rheumatology (Oxford). 2014;53:114-122. https:// doi.org/10.1093/rheumatology/ket317

38. Smits-Engelsman B, Klerks M, Kirby A. Beighton score: a valid measure for generalized hypermobility in children. J Pediatr. 2011;158:119-123.e4. https://doi.org/10.1016/j.jpeds.2010.07.021

39. Sohrbeck-Nøhr O, Kristensen JH, Boyle E, Remvig L, Juul-Kristensen B. Generalized joint hypermobility in childhood is a possible risk for the development of joint pain in adolescence: a cohort study. BMC Pediatr. 2014;14:302. https:// doi.org/10.1186/s12887-014-0302-7

40. Stinson JN, Kavanagh T, Yamada J, Gill N, Stevens B. Systematic review of the psychometric properties, interpretability and feasibility of self-report pain intensity measures for use in clinical trials in children and adolescents. Pain. 2006;125:143-157. https://doi.org/10.1016/j. pain.2006.05.006

41. Stommen NC, Verbunt JA, Gorter SL, Goossens ME. Physical activity and disability among adolescents and young adults with nonspecific musculoskeletal pain. Disabil Rehabil.
2012;34:1438-1443. https://doi.org/10.3109/096 38288.2011 .645112

42. Ting TV, Hashkes PJ, Schikler K, Desai AM, Spalding S, Kashikar-Zuck S. The role of benign joint hypermobility in the pain experience in Juvenile Fibromyalgia: an observational study. Pediatr Rheumatol Online J. 2012;10:16. https:// doi.org/10.1186/1546-0096-10-16

43. Tobias JH, Deere K, Palmer S, Clark EM, Clinch J. Joint hypermobility is a risk factor for musculoskeletal pain during adolescence: findings of a prospective cohort study. Arthritis Rheum. 2013;65:1107-1115. https://doi. org/10.1002/art.37836

44. Verbunt JA, Nijhuis $A$, Vikström $M$, et al. The psychometric characteristics of an assessment instrument for perceived harmfulness in adolescents with musculoskeletal pain (PHODAyouth). Eur J Pain. 2015;19:695-705. https://doi. org/10.1002/ejp.592

45. Verbunt JA, Seelen HA, Vlaeyen JW, et al. Pain-related factors contributing to muscle inhibition in patients with chronic low back pain: an experimental investigation based on superimposed electrical stimulation. Clin J Pain. 2005;21:232-240.

46. Verbunt JA, Seelen HA, Vlaeyen JW, et al. Disuse and deconditioning in chronic low back pain: concepts and hypotheses on contributing mechanisms. Eur J Pain. 2003;7:9-21. https:// doi.org/10.1016/S1090-3801(02)00071-X

47. Verbunt JA, Seelen HA, Vlaeyen JW, van der Heijden GJ, Knottnerus JA. Fear of injury and physical deconditioning in patients with chronic low back pain. Arch Phys Med Rehabil. 2003;84:1227-1232. https://doi.org/10.1016/ S0003-9993(03)00132-1

48. Verbunt JA, Smeets RJ, Wittink HM. Cause or effect? Deconditioning and chronic low back pain. Pain. 2010;149:428-430. https://doi. org/10.1016/j.pain.2010.01.020

49. Verbunt JA, Westerterp KR, van der Heijden GJ, Seelen HA, Vlaeyen JW, Knottnerus JA. Physical activity in daily life in patients with chronic low back pain. Arch Phys Med Rehabil. 2001;82:726730. https://doi.org/10.1053/apmr.2001.23182

50. Vlaeyen JW, Linton SJ. Fear-avoidance and its consequences in chronic musculoskeletal pain: a state of the art. Pain. 2000;85:317-332. https:// doi.org/10.1016/S0304-3959(99)00242-0

51. Walker LS, Greene JW. The Functional Disability Inventory: measuring a neglected dimension of child health status. J Pediatr Psychol. 1991;16:3958. https://doi.org/10.1093/jpepsy/16.1.39

52. Zekry OA, Ahmed MA, Elwahid HA. The impact of fatigue on health related quality of life in adolescents with benign joint hypermobility syndrome. Egypt Rheumatol. 2013;35:77-85 https://doi.org/10.1016/j.ej.2012.12.002 